\title{
The Effect of a Psychoeducation Intervention on Burden Among Caregivers of Persons with Schizophrenia in Medan
}

\author{
Jenny Marlindawani Purba ${ }^{1}$, Evi Karota Bukit ${ }^{2}$ \\ ${ }^{1}$ Department of Community and Psychiatric Nursing, University of Sumatera Utara, Indonesia \\ Jhuan_702@hotmail.com \\ ${ }^{2}$ Department of Community and Psychiatric Nursing, University of Sumatera Utara, Indonesia \\ evi_karota@yahoo.com
}

\begin{abstract}
Schizophrenia is a chronic mental illness that requires long treatment. Caring for schizophrenia in a long period caused a burden for caregivers who took care of a patients at home. Psychoeducational intervention may improve caregivers' outcomes. It was designed to help caregivers reduce their burden of care. This study was a quasi-experimental design to evaluatethe effect of a psychoeducation intervention on burden among caregivers of persons with schizophrenia at home. One hundred caregivers of schizophrenia persons were recruited and divided into the experimental and control groups. Of these, 50 participants in the experimental group received the psychoeducation intervention and the standard care was measured by the Zarit Caregiver Burden Scale. The caregiver intervention was held once a week for 5 weeks. Burden was measured before and after the intervention. An Independent $t$-test was conducted to determine the differences between group effect of the intervention and Paired t-test was used to examine the within group effect of the intervention. This study revealed that the mean score of the caregivers' burden in the experimental group was significantly lower than those in the control group after they received the intervention $(t=11.20, p<0.01)$. The psychoeducation intervention in this study indicated positive effects on decreasing the caregivers' burden of persons with schizophrenia. Future study should aim to provide a more accurate idea of the contribution of the different domains of caregiver intervention programs of this kind to reducing burden. It should also to investigate the ways of reducing burden of care.
\end{abstract}

Keywords- burden, caregiver, psychoeducation, schizophrenia

\section{INTRODUCTION}

Schizophrenia is a severe mental illness that affects the function of thinking, perception, cognition, emotion and motivation and can cause stress and burden for families, especially caregivers [1]. It is a common psychotic symptom and often considered as a serious mental illness. This is because people with schizophrenia are faced with a problem regarding poor psychotic symptoms in a long period [2].

The onset age is in early adulthood between the ages of 15 and 35 . In males, it begins $4-5$ years earlier (15-25 years) than in females (25-35 years) [3]. There are increasing numbers of people with schizophrenia living in various communities particularly in Medan. In 2016, the number of schizophrenia patients was 14.838 persons. The number of hospitalized patients with schizophrenia was 2.051, while that of patients visiting the outpatient department was 12.787. These data indicate an increasing prevalence of patients with schizophrenia; most of them were not hospitalized. They also showed that most of the schizophrenia cases presented at the outpatient department were patients who experienced relapse [4].

Schizophrenia does not cause disturbances for the patients only but also their families' life, colleagues and community [5]. Family caregivers experience a series of conflicts and tend to show emotional responses such as fear of violence, high levels of burden, stigma, frustration, sadness, anger, and timelessness [6]. Family caregivers also suffer from financial problems and lack of knowledge, in particular information about schizophrenia [7]. In addition, experiencing burden of care for a long period of time also affects the quality of life, health and functional status of the caregiver [8].

Previous studies conducted in Indonesia shows that caring for schizophrenia patients made a burden among caregivers. This condition had an effect to them physically, socially, and economically. Low finance also could be a problem in order to provide care for their members. A long treatment, severity of the illness, and high cost of medication could be the risk factor for financial burden among caregivers of persons with schizophrenia. In their study, there were $67.8 \%$ of caregivers who felt the burden [9]. 
The psychoeducation program is one of the psychosocial interventions that have been recommended to help both schizophrenia persons and caregiver. Nurses used this intervention as one of the strategies in order to provide information about schizophrenia, treatment, social skills, problem solving and the resources available [10]. In addition, the proven psychoeducation intervention may reduce the number of readmission among schizophrenia persons [11].

In Indonesia, most research in the area of psychiatric nursing focuses on cognitive therapy, behavioral therapy and health education group activities [12], [13]. However, the psychoeducation program has been implemented largely focused on cognitive therapy only. The methods used only for giving information about the disease and for problem solving course. There was no training for caregivers to improve their performance in caring for their loved ones. The effect of the program is also not optimal perceived by caregiver [13].

Until now, in Indonesia, there are a limited number of studies focusing psychoeducation interventionon caregiver in caring for schizophrenia persons. This program can provide a positive effect for caregiver. The outcome of the program is the presence of behavioral change towards better marked with strong motivation and consciousness of caregiver to provide optimal care for the caregiver. Therefore, this research focuses on the effects of psychoeducation interventiontoward the caregivers' burden to provide optimal care for persons with schizophrenia.

\section{METHODS}

The quasi-experimental study, two groups, pre-test and post-testdesign was employed in order to examine the effect of the psychoeducation intervention to reduce caregivers' burden in providing care for persons with schizophrenia. The sample size was calculated based on the power analysis technique with a significance level of 0.05 , power of 0.80 , and the effect size (d) was 0.6 that was obtained from a previous study [11].

Samples were recruited based on the inclusion criteria, then randomly assigned to either the experimental group or control group which used minimization random program. The experimental group received a 5-week intervention of psychoeducation and standard psychiatric outpatient care. Whereas, the control group received the standard care as a routine care provided by nurses at out-patient department. The participants were the primary caregivers of persons with schizophrenia who attended Outpatient-Department in psychiatric hospital, Medan Indonesia. One hundred participants met the inclusion criteria: (1) age 18 to 65 years old, (2) mentally alert, (3) able to understand and read bahasa Indonesia, (4) live with and care for a family member who at recruitment has met the Diagnostic and Statistical Manual of Mental Disorders (DSMIV-TR) diagnostic classification for schizophrenia for at least 1 year. The group met on a-weekly basis for 10 sessions, each lasting about two hours.

\section{A. Data collection}

The instrument used was the Zarit Caregiver Burden Scale (ZCBS). This instrument was used to measure caregivers' burden with Cronbach's alpha coefficient of 0.90 . The ZCBS was developed by Zarit and colleagues to measure subjective burden among caregiver of dementia. Its originally consist of 29 item scale. The researcher revised the instrument and ended up with a 20 -item scale based on clinical experience. Each item was measured using a Likert scale with five possible responses ranging from "never" (1) to "almost always" (5). Total scores ranged from 20 to 100 . The higher score of ZCBS indicated that higher burden on caregivers in caring for persons with schizophrenia.

The process of psychoeducation intervention included (1) orientation and engagement; (2) providing information about the nature of schizophrenia. the activities included the explaination of schizophrenia, signs and symptoms, etiology, early signs of relapse, diagnose, treatment, side effect and management of side effect; (3) sharing experience regarding caring for their loved ones; (4) modality therapy; (5) training; (6) making close relationship with schizophrenia's persons; (7) evaluating the caregivers' performance; (8) exploration of resources; and (10) termination. At completion, regarding ethical consideration, the researchers invited the caregivers in the control group who received standard care to participate in a 
similar psychoeducation group should they wish to do so, as the experimental group were effective.

\section{B. Ethical approval}

Ethical approval for the study was granted by the ethic committee Faculty of Nursing, University of Sumatera Utara, Medan Indonesia. Signed informed consent was obtained from 100 participants before intervention, and confidentiality was maintained.

\section{Data analysis}

The independent t-test test was applied to ascertain whether there was a significant difference pre and post-intervention between the control and experimental groups.

\section{RESULTS}

At the baseline, there were no significant differences of caregivers' burden between the experimental and control groups (Table 1). The mean score of caregivers' burden in the experimental group and the control group were $47.10(S D=7.22)$ and $47.74(S D=7.64)$.

TABLE I

PRE-TEST MEAN SCORE OF THE CAREGIVERS' BURDEN BETWEEN THE EXPERIMENTAL GROUP AND CONTROL GROUP

\begin{tabular}{|l|c|c|c|c|c|c|}
\hline Variable & \multicolumn{2}{|c|}{$\begin{array}{c}\text { Experimental group } \\
\mathrm{n}=50\end{array}$} & \multicolumn{2}{|c|}{$\begin{array}{c}\text { Control group } \\
\mathrm{n}=50\end{array}$} & \multirow{2}{*}{$t$} & \multirow{2}{*}{$p$} \\
\cline { 2 - 5 } & $\mathrm{M}$ & $\mathrm{SD}$ & $\mathrm{M}$ & $\mathrm{SD}$ & & \\
\hline Burden & 47.10 & 7.22 & 47.74 & 7.64 & 0.53 & 0.59 \\
\hline
\end{tabular}

Table 2 shows the comparison of the caregivers' burden mean score within the experimental group and control group. Caregivers in the experimental group showed there was a statistically significant difference between the pre-test and post-test mean score on caregivers' burden $(t=-16.17, p<0.01)$. Meanwhile, caregivers in the control group claimed that there was no significant difference between pre-test and post-test mean score of caregivers' burden $(t=-1.58 ; p>0.05)$.

\section{TABLE II}

COMPARISONS OF THE PRE-TEST AND POST-TEST MEAN SCORES OF THE CAREGIVERS' BURDEN WITHIN THE EXPERIMENTAL GROUP AND CONTROL GROUP

\begin{tabular}{|c|c|c|c|c|c|c|}
\hline Variable & \multicolumn{2}{|c|}{ Pre-test } & \multicolumn{2}{|c|}{ Post-test } & \multirow{2}{*}{$*$} & \\
\cline { 2 - 5 } & $\mathrm{M}$ & $\mathrm{SD}$ & $\mathrm{M}$ & $\mathrm{SD}$ & $t$ & $p$ \\
\hline $\begin{array}{c}\text { Experimental group } \\
\text { ZCBS }\end{array}$ & 47.10 & 7.22 & 63.66 & 4.90 & -16.17 & 0.00 \\
\hline $\begin{array}{c}\text { Control group } \\
\text { ZCBS }\end{array}$ & 47.74 & 7.64 & 49.36 & 5.74 & -1.58 & 0.12 \\
\hline
\end{tabular}

In order to examine the effect of the psychoeducation intervention, the post-test mean scores of caregivers' burden were examined by using independent $t$-test (Table 3). The mean of post-test score of caregivers' burden showed significant difference between the experimental group thanin the control group $(t=11.20, p<0.01)$.

TABLE III

POST-TEST MEAN SCORE OF THE CAREGIVERS' BURDEN BETWEEN THE EXPERIMENTAL GROUP AND CONTROL GROUP

\begin{tabular}{|c|c|c|c|c|c|c|}
\hline \multirow[t]{2}{*}{ Variable } & \multicolumn{2}{|c|}{$\begin{array}{c}\text { Experimental } \\
\text { group } \\
\mathrm{n}=50\end{array}$} & \multicolumn{2}{|c|}{$\begin{array}{c}\text { Control group } \\
n=50\end{array}$} & \multirow[t]{2}{*}{$t$} & \multirow[t]{2}{*}{$p$} \\
\hline & $\mathrm{M}$ & SD & $\mathrm{M}$ & SD & & \\
\hline \multicolumn{7}{|l|}{ Burden } \\
\hline $\begin{array}{l}\text { Post- } \\
\text { test }\end{array}$ & 63.66 & 4.90 & 51.44 & 5.95 & 11.20 & 0.00 \\
\hline
\end{tabular}

\section{DISCUSSION}

There were no significant difference in caregivers' burden between the experimental and control group before entering the psychoeducation intervention. In contrast, the mean score of the caregivers' burden after receiving the intervention demonstrated significant difference between the experimental and control groups. The present study showed that the psychoeducation intervention has positive effect for improving caregivers' preparedness in caring for persons with schizophrenia.

The improvement of caregivers' burden in this study was due to of the application of the psychoeducation intervention. Improvement of preparedness may help them to enhance their readiness to care for their love ones with schizophrenia. A psychoeducation in this study consisted of assess, commitment, teaching, training, and evaluation. The researchers assessed the knowledge, skills, and belief of caregivers in the beginning. The researchers gain deep understanding about belief of caregivers toward schizophrenia. Teaching activities in this study provided information about the nature of schizophrenia that included definition, signs and symptoms, early signs of relapse, medication and side effects, and management of side effect as well.

A psychoeducation program is a strategy that teaches patients and their families about illness, treatment s, communication skills, problem solving, 
and available resources [10]. In the context of family caregiving, psychoeducational interventions are commonly used for persons with schizophrenia as well as their family caregivers in Western countries and Asian countries.

Several studies in Western countries showed that psychoeducation program interventions were effective for reducing the burden of the caregivers, reduce relapse rates, increased knowledge both patients and caregivers. As well as few studies conducted in Asian countries indicated that the psychoeducation program intervention improved the family functioning, changed family attitude towards relatives, increased family satisfaction, social support, reduce burden, and effective for rural community settings. In this study, the education the researchers provided for family caregivers was helpful, useful, and necessary for them in caring for people with schizophrenia. The researchers also inspired them to be ready to caring for their members. In this study, the researchers provided a book care as guideline and video about schizophrenia for each caregiver. The researchers also used individual and group approach to conduct the intervention. Individual and group approach facilitated by researchers, and interaction between participants within groups meeting were clearly defined. By providing psychoeducation interventions, caregivers can overcome the problems that arise related to patient behavior [14]. The present study was supported with a study conducted by [15]. It found that psychoeducation intervention has positive effects to reduce burden of care.

In this study, the control group under standard outpatient department, care had shown little improvement in most of caregivers. In fact, the standard may be explained by the facts and standard care. There results may be supported. Those psychiatric services in Medan are not provided in a systematic and comprehensive manner relevant to the caregivers' needs.

Follow-up sessions by using home visit strategy and face to face are also important methods for achieving the outcome. The researcher evaluated the implementation of objectives; action plan and performance during visits to the caregivers' house at the fourth week and the face to face follow up at the fifth week. The researcher also discussed any difficulties implement the plans in fourth week and fifth week and helped them to find alternative strategies to solve the difficulties in performing their care. The researchers also provided positive reinforcement for successful caregivers in performing their care. Most caregivers reported feeling satisfied with this program intervention.

\section{CONCLUSIONS}

The findings clearly indicated that the psychoeducation intervention had positive effects on caregivers' burden when compared with those who received standard care. Further study using mixed methods with longer period of follow-up is recommended to evaluate the long-term effects of the caregivers' outcomes and schizophrenias' in the community. Future study should aim to provide a more accurate idea of the contribution of the different domains of caregiver intervention programs of this kind to reducing burden. It should also to investigate the ways of reducing burden of care.

\section{ACKNOWLEDGEMENT}

The study was supported by a scholarship awarded from the Institution of Research, University of Sumatera Utara, Medan Indonesia.

\section{REFERENCES}

[1] X. Huang, B. Hung, F. K. Sun, J. Lin, and C. Chen. The experiences of carers in Taiwanese culture who have long-term schizophrenia in their families: A phenomenological study. Journal of Psychiatric \& Mental Health Nursing, vol 16, pp. 874-883, May, 2009.

[2] M.Viron, T. Baggett, M. Hill, and O. Freudenreich. Schizophrenia for primary care providers: How to contribute to the care of a vulnerable patient population. The American Journal of Medicine. vol 12, pp 223 230. March, 2012

[3] P. Wright, and J. E. Kraus. Schizophrenia and related disorders. In P. Wright, J. Stern, and M. Phelan Ed. Core Psychiatry. London: Saunders Elsevier, 2012.

[4] Psychiatric Medan Hospital. Medical record of schizophrenia's patients, Medan, 2015

[5] E.Ingkiriwang. Schizophrenic patients and the effect their illness of family members [Special issue] [the Indonesia language]. Journal Indonesia Medical Association, vol 36, 2010.

[6] E. Papastavrou, A. Charalambous, H. Tsangari, and G. Karayiannis. The cost of caring: The relative with schizophrenia. Scandinavian Journal of Caring Sciences, vol

24, pp. 817-823, Jan. 2010.

[7] N. Small, H. Joanne, and Newell, R. Carer burden in schizophrenia: considerations for nursing practice. Mental Health Practice, vol 14, pp. 22-25, Dec. 2010

[8] A. Caqueo-Urizar, J. Guierrez-Maldonado, M. Ferrer-Garcia, C. Penaloza-Salazar, D. Richards-Araya, and A. Cuadra-Peralta. (2011). Attitudes and burden in relatives of patients schizophrenia in a middle income country. Revista de Psiquaitria y Salud Mental, vol 12, July, 2012.

[9] P. Darwin, G. Hadisukanto, and S. D. Elvira. Burden and emotional expression among caregivers of schizophrenia patients in a mental health 
hospital. Journal Indonesia Medical Association, vol 63, pp. 46-61, Feb 2013.

[10] S. W. Chan, B. Yip, S. Tso, B. Cheng, and W. Tam. Evaluation of a psychoeducation program for Chinese clients with schizophrenia and their family caregivers. Patient Education and Counseling, vol 75, pp. 67-76, Aug. 2009.

[11] S. Glynn, E. Randolph, T. Garrick, and A. Lui. A proof of concept trail of an online psychoeducational program for relatives of both veterans and civilians living with schizophrenia. Psychiatric Rehabilitation Journal, vol 33, pp. 278-287, Apr.1, 2010.

[12] C.Marchira. Pengaruh intervensi psikoedukasi interaktif singkat tentang skizofrenia terhadap pengetahuan caregiver, keteraturan kontrol, ketaatan pengobatan, dan kekambuhan pada penderita gangguan psikotik fase awal di Jogjakarta. Thesis, Univ. of Gajah Mada,
Jogjakarta, July, 2012. [Online]. Available http://lib.ugm.ac.id/digitasi/index.

[13] Wiyati, D. Wahyuningsih, dan E. D. Widayanti, E. D. Pengaruh psikoedukasi keluarga terhadap kemampuan keluarga dalam merawat klien isolasi sosial. Jurnal Keperawatan Soedirman, vol 5, pp. 85-94, July, 2010.

[14] A. K.Koolaee, and A. Etemadi. The outcome of family interventions for the mothers of schizophrenia patients in Iran. [Original]. International Journal of Social Psychiatry, vol 56, pp. 634-646, Oct. 2010.

[15] A. A. Hasan, P. Callaghan, and J. S. Lymn. Evaluation of the impact of a psychoeducation intervention on knowledge levels and psychological outcomes for people diagnosed with schizophrenia and their caregiver in Jordan: a randomized controlled trial, vol 14, pp. 17-24, Sept. 2014. 